\title{
Endometrial and placental protein markers and ovarian steroids in serum during in-vitro fertilization cycles
}

\section{N.A.Bersinger ${ }^{1}$, A.W.Brandenberger and M.H.Birkhäuser}

Department of Obstetrics and Gynaecology, Division of Endocrinology, University of Berne, Schanzeneckstrasse I, Berne $\mathrm{CH}-3012$, Switzerland

'To whom correspondence should be addressed

The objective of this study was to find the earliest time at which it was possible to detect clinical pregnancy in an invitro fertilization (IVF) treatment cycle supported with human chorionic gonadotrophin (HCG), and also retrospectively to diagnose abnormal ovarian- or endometriumrelated situations in failure cycles. Serum samples were taken in 41 IVF cycles at frequent intervals from the beginning of ovarian stimulation until menstrual bleeding occurred or a pregnancy was established. Concentrations of oestradiol, progesterone, placental protein 14 (PP14), pregnancy-specific $\beta 1$-glycoprotein $\left(\mathrm{SP}_{1}\right)$, and pregnancyassociated plasma protein A (PAPP-A) were determined in the serum samples using commercially available (steroid) or purpose-developed (protein) immunoassays. The cycles were retrospectively distributed into four outcome groups: (i) fertilization failure (FF, $n=8$ ); (ii) implantation failure (IF, $n=10$ ); (iii) 'interaction' (embryo-endometrium) cycle (IC, $n=14$ ), and (iv) clinical pregnancy $(\mathrm{CP}, n=9)$. The embryo-endometrium interaction was detected by a rise in $\mathrm{SP}_{1}$ in 23 cycles $(70 \%$ of embryo transfers) at a time when endogenous HCG was still masked by external support. Early ('false') positive $\mathrm{SP}_{1}$ concentrations were observed in two out of eight and five out of 14 cases in groups FF and IC respectively, but never amongst the ongoing pregnancies (CP). PAPP-A did not distinguish pregnancy from the other outcomes. The PP14/progesterone ratio was lower, later in the cycle, in $\mathrm{CP}$ than in the other groups. We conclude that, while it is not possible to predict the outcome of a given IVF cycle earlier than 2 weeks after embryo transfer, the hormonal patterns can be used to detect abnormalities (e.g. endometrial asynchrony) which may be useful for subsequent treatment cycles in the same patient.

Key words: endometrium/implantation/placental protein 14/ pregnancy-specific $\beta$ 1-glycoprotein/progesterone

\section{Introduction}

In order to organize treatment by in-vitro fertilization (IVF) and embryo transfer with least strain on patients and staff, it would be an advantage to know the outcome, be it positive or negative, of a given cycle as early as possible. In addition, there are various reasons for failure to establish an ongoing pregnancy: ovarian- or endometrium-related situations could be responsible as well as an impairment of the dialogue between maternal tissues and the embryo; the importance of synchrony, or rather the maximal allowed extent of deviation from it, between endometrium and embryo also requires assessment. At early stages such as during the first 3 weeks after embryo transfer, these objectives can only be met by biochemical investigation.

Amongst the described pregnancy-specific proteins, human chorionic gonadotrophin (HCG) is the first to be produced and released by the embryo, and pregnancy is usually detected by measurement of this hormone in the maternal serum; concentrations $>40 \mathrm{mIU} / \mathrm{ml}$ would theoretically occur from day 13 after embryo transfer. The administration of exogenous HCG during luteal phase support, however, masks the embryoderived fraction of this hormone in the mother's serum during this period (i.e. days 12-15 after embryo transfer). A typical serum HCG concentration would be $40-60 \mathrm{mIU} / \mathrm{ml} 24 \mathrm{~h}$ after an injection of $1000 \mathrm{IU}$ of HCG. We therefore decided to test the usefulness of a very sensitive enzyme-linked immunosorbent assay (ELISA) for a pregnancy-specific $\beta 1$-glycoprotein $\left(S_{1}\right)$ which, like $H C G$, is produced by the trophoblast but which is biochemically unrelated to it. $\mathrm{SP}_{1}$ can only be detected in the serum from $\sim$ day 18 or 20 after embryo transfer by commercial enzyme or radioimmunoassay respectively. The more sensitive enzyme assay developed by Grenner (1978) has now been withdrawn from the market. With the aim of testing the usefulness of $\mathrm{SP}_{1}$ for reliable diagnosis of early pregnancy in the presence of exogenous $\mathrm{HCG}$, we have developed a highly sensitive $(0.02 \mathrm{ng} / \mathrm{ml})$ microplate enzyme immunoassay for this protein.

In this context, we also studied the possible reasons for failure in those cycles not leading to pregnancy; we considered whether $S_{1}$ and pregnancy-associated plasma protein $A$ (PAPP-A), a large glycoprotein normally produced in pregnancy by the trophoblast but for which ectopic production had been demonstrated (Schindler et al., 1984), would show distinct serum concentration patterns according to outcome. Another, probably better candidate for such diagnosis is endometrial placental protein 14 (PP14 or $\alpha 2-$ PEG) which is a major secretory product of the endometrium in the late luteal phase (Bell et al., 1986) and whose production is positively correlated with that of progesterone (Bell and Drife, 1986). However, this relationship is a complex one with at least one unknown factor in between, which is illustrated by several observations: (i) there is a time delay of several days; (ii) serum PP14 is strongly reduced in pregnancies resulting from ovum donation 
(Johnson et al., 1993); and (iii) in contrast to prolactin, it is not possible to stimulate PP14 production in vitro by endometrial explants exposed to progesterone (Bersinger et al., 1995b). PP14 is also produced by the Fallopian tubes (Maguiness et al., 1993) and serous ovarian cysts (Riitinen, 1992). Moreover, it can be detected in the serum of women who have undergone hysterectomy (Seppala et al., 1987; plus our own unpublished observations). In ovarian stimulation and its associated high steroid concentrations, the factors influencing the release patterns of PP14 and other secretory products are likely to be altered. In this study, we assessed serum PP14 in relation to progesterone concentration using the PP14/progesterone ratio in four groups of patients (see below). We found that this ratio, from around the time of implantation, was lower in the group of patients with ongoing pregnancies than in the others, which indicates that in the implantation failure and 'interaction' cycles (an early form of biochemical pregnancy), the endometrial PP14 response was too fast to match the developmental stage of the embryo (asynchrony).

\section{Materials and methods}

\section{Patients and in-vitro fertilization protocols}

A total of 37 patients (mean age 32.1, range 25-40 years) provided 41 cycles leading to oocyte retrieval and inclusion in this study. Ovarian stimulation was performed according to an identical protocol in all of them: $0.1 \mathrm{mg}$ s.c. per day of gonadotrophin-releasing hormone (GnRH) agonist (Decapeptyl; Ferring, Dubendorf, Switzerland) starting from the mid-luteal phase of the preceding cycle ('long' protocol) until the day of HCG administration (day of oocyte retrieval -2), human menopausal gonadotrophin (HMG, Pergonal; Serono, Zug, Switzerland) 150-300 IU/day for 9-12 days, and $10000 \mathrm{IU}$ of HCG (Profasi; Serono) to induce ovulation. Assessment of functional follicular maturation was by ultrasound examination (by the same clinician, A.W.B., in all patients) together with serum oestradiol measurement. Transvaginal oocyte retrieval was performed under light sedation and transvaginal ultrasound guidance $34-38 \mathrm{~h}$ after HCG administration. The heparin-containing flushing medium used was obtained from Medi-Cult, Copenhagen, Denmark. The oocytes were cultured in IVF medium (Medi-Cult), inseminated with 50000 100000 motile spermatozoa prepared by either Percoll gradient or swim-up in the same medium. The culture medium was replaced the following day after microscopic assessment of fertilization. Two or three embryos were transferred 2 days after oocyte retrieval. Luteal support was given by injecting $1000 \mathrm{IU}$ of $\mathrm{HCG}$ on the day of embryo transfer and every second day thereafter, until a clinical pregnancy was established or a menstrual period occurred. A serum sample was collected from each patient on the following days, with exceptions due to patient availability: first day of HMG stimulation, -1 week later, on HCG day (day of oocyte retrieval -2), oocyte retrieval day, embryo transfer day (day of oocyte retrieval +2 ), day of oocyte retrieval $+11( \pm 2)$ days, day of oocyte retrieval $+18( \pm 2)$ days. Oestradiol was determined immediately by routine laboratory procedure, and progesterone, endometrial PP14, SP 1 , and PAPP-A were assayed at the end of the cycle in batches as described later.

The patients were assigned to one of four groups retrospectively, according to outcome: (i) fertilization failure (FF, no transfer), $n=$ 8; (ii) implantation failure (IF), i.e. no $\mathrm{SP}_{1}$ rise at any time after day of embryo transfer+12, $n=10$; (iii) 'interaction cycle' (IC), i.e. $\mathrm{SP}_{1}$ rise between day of embryo transfer +12 and day of embryo transfer $+17, n=14$; (iv) clinical ongoing pregnancy (CP), $n=9$. No case of 'biochemical pregnancy' (i.e. an HCG value $>1000 \mathrm{mIU} / \mathrm{ml}$ without ongoing pregnancy) was encountered.

\section{Immunoassays of hormones and marker proteins}

Oestradiol was determined immediately after receipt of the serum, by lanthanide immunofluorometric assay (Delfia; Wallac, Turku, Finland) according to the manufacturer's instructions. Progesterone was measured by radioimmunoassay using a coated tube kit (Coat-a-count; DPC, Los Angeles, CA, USA). The sample volume was $100 \mu \mathrm{l}$; and for sera obtained between oocyte retrieval and day of oocyte retrieval +11 inclusive (day of oocyte retrieval +18 in some cases, which included the whole CP group) a 1:10 dilution was made with zero standard prior to assay. Intact dimeric HCG was determined from day 13 after oocyte retrieval by Delfia methodology (Wallac).

ELISAs, developed in our laboratory, were used to assay PPI4, $\mathrm{SP}_{1}$, and PAPP-A as follows: PP14 was determined in a sandwich procedure with different antibodies for immobilization and detection. Microtitre plate strips (Maxisorp F16; Nunc, Roskilde, Denmark) were coated with an immunoglobulin (Ig) $\mathrm{G}$ preparation of a polyclonal rabbit antibody, raised against PP14 purified from early pregnancy (13 weeks maximum) amniotic fluid, at a concentration of $10 \mu \mathrm{g} / \mathrm{ml}$ in sodium carbonate buffer $\left(50 \mathrm{mM}, \mathrm{pH} 9.6\right.$, overnight at $\left.4^{\circ} \mathrm{C}\right)$. The reaction volume was $100 \mu 1 /$ well. Excess sites were blocked with bovine serum albumin (BSA; Fluka, Buchs, Switzerland) at $5 \mathrm{mg} / \mathrm{ml}$ in phosphate-buffered saline (PBS) at $\mathrm{pH} 7.4$ for at least $2 \mathrm{~h}$ at room temperature. Patient sera were diluted 1:2 with assay buffer (AB), i.e. PBS containing BSA (Fluka, $20 \mathrm{mg} / \mathrm{ml}$ ) and nonionic detergent (Emulsit, Daiichi, Kogyo, Japan, 0.05\% v/v). After a $90 \mathrm{~min}$ incubation at $37^{\circ} \mathrm{C}$ the plate was washed with PBS containing Tween-20 (PBST, Surfact-Amps; Pierce, Rockford, IL, USA). Then monoclonal anti-PP14 prepared by Riitinen et al. (1991) and kindly supplied by Dr M.Seppala, University of Helsinki, Finland, was added at a dilution of $1: 10000$ in $\mathrm{AB}$, and the plate incubated for a further $60 \mathrm{~min}$ at $37^{\circ} \mathrm{C}$. After another washing step, peroxidase-conjugated goat anti-mouse IgG (ELISA grade, Bio-Rad, Hercules, CA, USA, dilution 1:3000 in $\mathrm{AB}$ ) was added and the plate incubated again as before. After extensive washing the amount of bound enzyme was determined with perborate $(0.03 \%)$ as a substrate and ortho-phenylenediamine $(0.8 \mathrm{mg} / \mathrm{ml})$ as a chromogen (both from Sigma, St Louis, USA) in a citrate/phosphate buffer (100 mM, pH 5.0). Using this protocol, the inherent high specificity of the monoclonal antibody was combined with high assay sensitivity $(0.02 \mathrm{ng} / \mathrm{ml})$.

A two-step sandwich ELISA procedure was used to determine $\mathrm{SP}_{1}$ in an assay volume of $200 \mu \mathrm{l} /$ well. Maxisorp plates were coated with rabbit polyclonal anti-SP, IgG (Dako, Glostrup, Denmark) at $10 \mu \mathrm{g} / \mathrm{ml}$ and post-coated with BSA as above (see PP14). Patient serum was diluted $1: 2$ in $A B$ (the same as for PP14), added to the wells and incubated for $90 \mathrm{~min}$ at $37^{\circ} \mathrm{C}$. After washing the plate with PBST, the enzyme conjugate (HRP-anti-SP 1 , prepared with the twostep glutaraldehyde method and obtained from Dako (but now discontinued) was added at $0.5 \mu \mathrm{g} \mathrm{IgG/ml} \mathrm{in} \mathrm{AB}$ and the plate incubated another $60 \mathrm{~min}$ at $37^{\circ} \mathrm{C}$. Subsequent washing and development of peroxidase with ortho-phenylene-diamine $(200 \mu \mathrm{l} /$ well $)$ was as described for PP14. Under these conditions, the sensitivity of the $\mathrm{SP}_{1}$ assay was a final $0.02 \mathrm{ng} / \mathrm{ml}$ which, at the minimum serum dilution used here, resulted in a practical sensitivity of $0.04 \mathrm{ng} / \mathrm{ml}$. Calibration was done using commercial standards ('Enzygnost-SP') obtained from Behringwerke (Marburg, Germany).

The ELISA method used for the determination of PAPP-A has been described previously (Bersinger et al., 1995a). A buffer system different from that in $\mathrm{SP}_{1}$ and PP14 assays was used for reasons of lower background and resulting increased sensitivity. Briefly, Maxisorp microplate strips were coated with polyclonal rabbit anti-PAPP- 


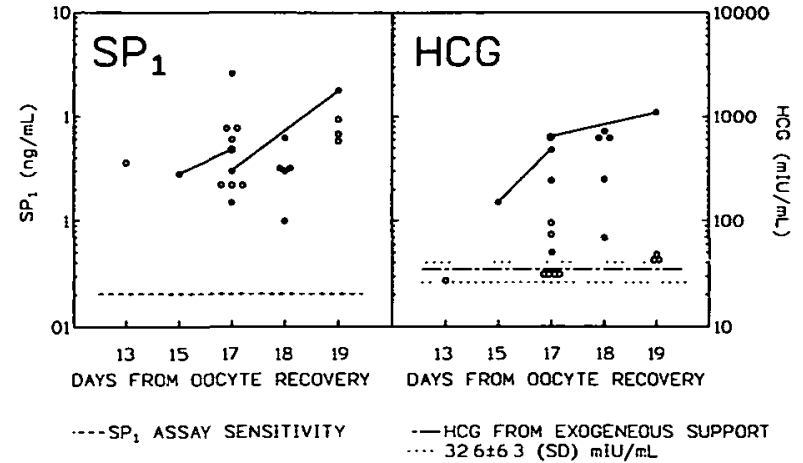

Figure 1. Detection of implantation by serum pregnancy-specific $\beta 1$-glycoprotein $\left(\mathrm{SP}_{1}\right)$ and human chorionic gonadotrophin (HCG). Individual readings obtained between the day of oocyte retrieval +13 and the day of oocyte retrieval +19 for 'interaction' group (IC; no ongoing pregnancy, open circles) and clinical pregnancy group (CP; filled circles). Two patients assayed twice are shown by pairs of points joined by solid lines.

A IgG, obtained from Dako but absorbed prior to use in ELISA, over an immobilized fraction of pregnancy serum filtrate $<300000 \mathrm{kDa}$ to remove anti-SP, and other contaminating activities directed at pregnancy serum constituents of lower molecular weight. After coating with $2 \mu \mathrm{g} \mathrm{IgG/ml} \mathrm{at} \mathrm{pH} 9.6$ and blocking of the excess sites with BSA (Fluka) at $5 \mathrm{mg} / \mathrm{ml}$ in PBS, the assay was run in PBS containing $0.5 \%$ non-fat milk proteins ('Blotto', obtained from Pierce). The same buffer was used for the second incubation with peroxidaseantibody conjugate which was also obtained from Dako and used without prior treatment at a 1:500 dilution. Assay sensitivity was $0.0036 \mathrm{mIU} / \mathrm{ml}$ [World Health Organization (WHO) reference preparation $78 / 610=100 \mathrm{mIU} / \mathrm{ml})$ ], intra- and interassay coefficients of variation were 4.3 and $10.2 \%$ respectively.

\section{Results}

\section{Detection of pregnancy}

We were unable to distinguish the clinical pregnancies from the outcome groups IF and IC, prior to day 15 after oocyte retrieval, by single serum determination of $\mathrm{PP} 14, \mathrm{SP}_{1}$, or PAPP-A. In 23 out of the 33 cycles with embryo transfer $(70 \%), \mathrm{SP}_{1}$ was positive on at least one occasion on or after the day of oocyte retrieval +13 . Figure 1 shows that these values were between one and two orders of magnitude above the assay sensitivity and that $\mathrm{SP}_{1}$, at this stage, did not distinguish between ongoing pregnancies and the IC group. HCG, on the other hand, tended to be higher with advancing time in the CP group but it could not be used as an early discriminator because of the exogenous hormone given for luteal support. PAPP-A, structurally different from HCG and $\mathrm{SP}_{1}$ but also primarily of trophoblastic origin, could not be used to detect pregnancies even on the day of oocyte retrieval +24 . Figure 2 shows individual PAPP-A patterns and illustrates patient-to-patient variation irrespective of cycle stage or outcome.

\section{Abnormal $S P_{1}$ patterns}

Figure 3 shows the range of $\mathrm{SP}_{1}$ patterns obtained in the nine $\mathrm{CP}$ patients as a function of time. The dashed lines represent the 'abnormal' $S P_{1}$ curves found in six out of the 14 IC group

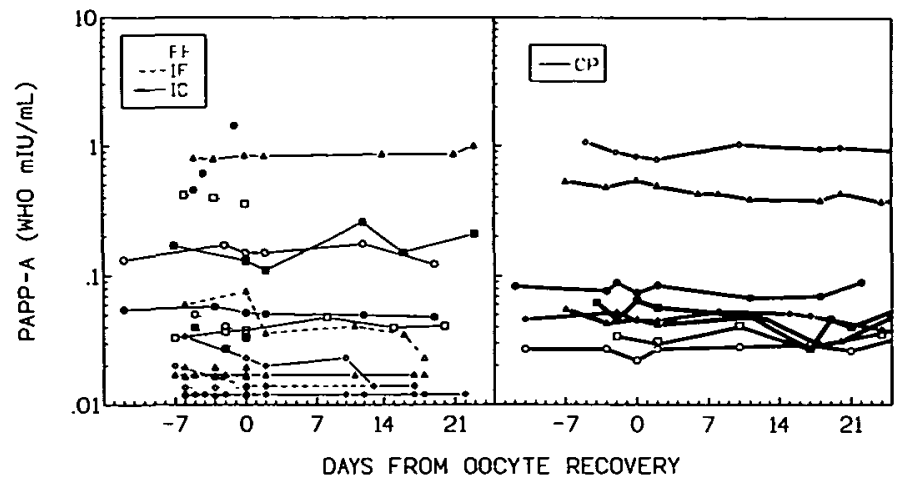

Figure 2. Serum pregnancy-associated plasma protein A (PAPP-A) in individual cycles. Left panel, fertilization failures (FF; dotted lines), implantation failures (IF; dashed lines), and positive implantation (by $\mathrm{SP}_{1}$ ) cycles (solid lines) in individual patients shown by various symbols. Right panel, clinical pregnancies (CP).

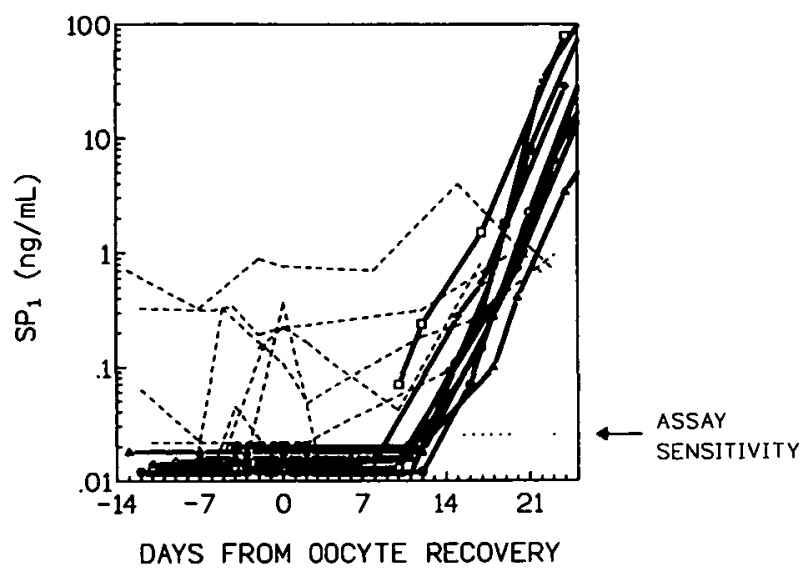

Figure 3. Individual serum pregnancy-specific $\beta 1$-glycoprotein $\left(\mathrm{SP}_{1}\right)$ patterns in clinical pregnancies (CP, solid lines) and in six cases out of the 14 'interaction cycles' (IC) with abnormal $\mathrm{SP}_{1}$ concentrations on or before embryo transfer (dashed lines). In the remaining $\mathrm{IC}$ cycles, $\mathrm{SP}_{1}$ patterns followed those in the $\mathrm{CP}$ cycles until the day of oocyte retrieval +14 to 17 , then the $S_{1}$ values fell to below assay sensitivity.

cycles with positive $\mathrm{SP}_{1}$ after the day of oocyte retrieval +13 but without ongoing pregnancy (the remaining IC group cycles had undetectable $S_{1}$ until around the day of oocyte retrieval +11 , when they started to rise like the $C P$ group but by the day of oocyte retrieval +18 they were declining). No 'abnormal' $\mathrm{SP}_{1}$ pattern was observed in the nine cycles where clinical pregnancy occurred. Moreover, they were never seen in the IF group, i.e. $\mathrm{SP}_{1}$ was never positive before the day of oocyte retrieval +2 without being positive at least once after the day of oocyte retrieval +13 . Commercially available radioimmunoassays for $\mathrm{SP}_{1}$ would not have yielded a positive result in any of the six above-mentioned abnormal patterns, and the pregnancies would only have been detected between day 19 and 24 after oocyte retrieval, i.e. when HCG concentration would anyway have been increased in spite of exogenous support.

\section{Steroid hormones}

Oestradiol followed a constant pattern according to the response to ovarian stimulation (data not shown). Progesterone concen- 


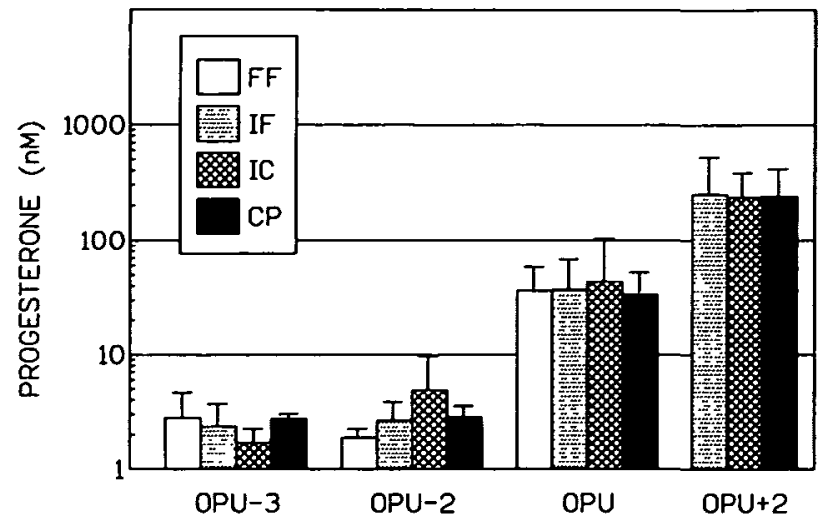

Figure 4. Mean + SD of serum progesterone concentrations in the four outcome groups (fertilization failure, FF; implantation failure, IF; interaction cycle, IC; and clinical pregnancy, CP) on four selected days around oocyte retrieval. OPU $=$ day of oocyte retrieval.

trations 3 and 2 days before oocyte retrieval, on the retrieval day itself as well as on the embryo transfer day (day of oocyte retrieval +2) are presented on Figure 4 as means plus SD for each day and outcome group. There were no statistically significant differences, but the IC group was noticeable because serum progesterone was three times higher on the day of oocyte retrieval -2 than one day earlier (day of oocyte retrieval -3 ). In the other three groups (importantly, in the pregnancy group) no such early sharp increase was observed.

\section{PP14 and the implantation window}

PP14 consistently increased over several orders of magnitude during the middle of the luteal phase in all groups examined. Before oocyte retrieval, there was considerable variation in PP14 since by using the highly sensitive and specific monoclonal immunoassay we found that in the majority of cases PP14, present probably through gestagenic stimulation from the previous luteal phase, was cleared to below the assay sensitivity while in others this was not the case. Such nondisappearance was observed at a higher frequency in the FF group (five out of eight) than in the others combined (10 out of 33). The kinetics of the endometrial secretory response to progestagenic stimulation was assessed by the PPI4/ progesterone ratio. Time courses of this ratio are shown in Figure 5. There was no outcome-related difference between the four groups in the proliferative phase since PP1 4 depended largely on the previous cycle (rate of disappearance). In the luteal phase, however, we observed a consistently less pronounced increase in PP14/progesterone ratio in the $\mathrm{CP}$ group (Figure 5A and hatched area in Figure 5B) than in the two other groups, IF and IC (there was no difference between IF and IC, Figure 5B). Table I shows the medians of all available measurements at the day of oocyte retrieval +2 , between the days of oocyte retrieval +10 and +12 inclusive, and between the days of oocyte retrieval +17 and +21 inclusive, for both ongoing pregnancy (CP) and confounded nonpregnancy (IF+IC) cycles; it illustrates that the observed effect on the PP14 to progesterone ratio was not only due to high progesterone concentrations observed in pregnancy, but also to a slow or retarded production of PP14.

\section{Discussion}

In this study, firstly we have attempted to characterize better the running of IVF cycles for staff and patient convenience by improving implantation and pregnancy detection. Secondly, retrospective analysis of previous cycles was undertaken with the aim of refining the diagnosis of failed IVF attempts.

We tried to find a means of detecting a pregnancy in an IVF cycle in the presence of exogenous $H C G$, which is often administered as a luteal phase support. Therefore, we set up a method for the detection of very low concentrations of $\mathrm{SP}_{1}$, which is biochemically different from HCG. With this sensitive assay (but probably not with a commercial radioimmunoassay for $\mathrm{SP}_{1}$ ) it was possible to diagnose an implantation 1 or 2 days before it would have been detected by the presence of excess HCG over the exogenous level. However, SP, did not distinguish between ongoing and biochemical pregnancies at this stage. The benefit, if any, of $\mathbf{S P}_{1}$ determinations over measurements of HCG for pregnancy detection therefore seems to be limited to a comparatively short period. Overall estimates of HCG remain the most reliable method of detecting early pregnancy especially if it is not used for luteal phase support. However, the $\mathrm{SP}_{1}$ results might help to decide whether or not luteal support should be continued, and determinations of this protein are therefore indirectly beneficial.

Another structurally different trophoblast marker, PAPP-A, showed at the high assay sensitivity of $0.02 \mathrm{WHO} \mathrm{mIU} / \mathrm{ml}$ used here, notable patient-to-patient variation, but no pregnancy-related increase in serum concentration before 25 days after oocyte retrieval. Being a very large molecular entity, its concentration starts to rise later (in natural cycles around the day of day luteinizing hormone surge+35). Secondly, SP, could be used, together with progesterone and PP14, for the retrospective detection of potentially abnormal cycles, but on condition that the highly sensitive ELISA (and not the commercial radioimmunoassays) is used. We do not know what causes the appearance of low-level $S_{P_{I}}$ around the hypothetical time of fertilization, but we have observed it before and a biochemical investigation has been undertaken; it has shown that this 'abnormal' SP, was not different from the trophoblast derived protein found at high concentrations in pregnancy serum (Bersinger, 1985). Production of $\mathrm{SP}_{1}$ has not been found in tissues other than the placenta, although Klopper et al. (1986) have detected it in the seminal fluid. It was thus included in the group of pregnancy-specific rather than pregnancy-associated proteins (Chard and Grudzinskas, 1985). PAPP-A, a member of the group of pregnancy-associated proteins, has been found in decidua (Schindler et al., 1984), seminal plasma (Klopper et al., 1986) and non-pregnancy serum (Bischof et al., 1981; Klopper et al., 1985; this study). Other pregnancy-associated proteins are produced by maternal tissue under stimulation (such as pregnancy zone protein by maternal plasma cells reacting to oestrogen). With the increased sensitivities of immunoassays for all these markers it is likely that the boundaries between these formerly well-defined groups will become less well-defined in future. Assays defined by a high specificity of the antibodies involved will recognize the 'true' antigen even at very low concentration, except if a 

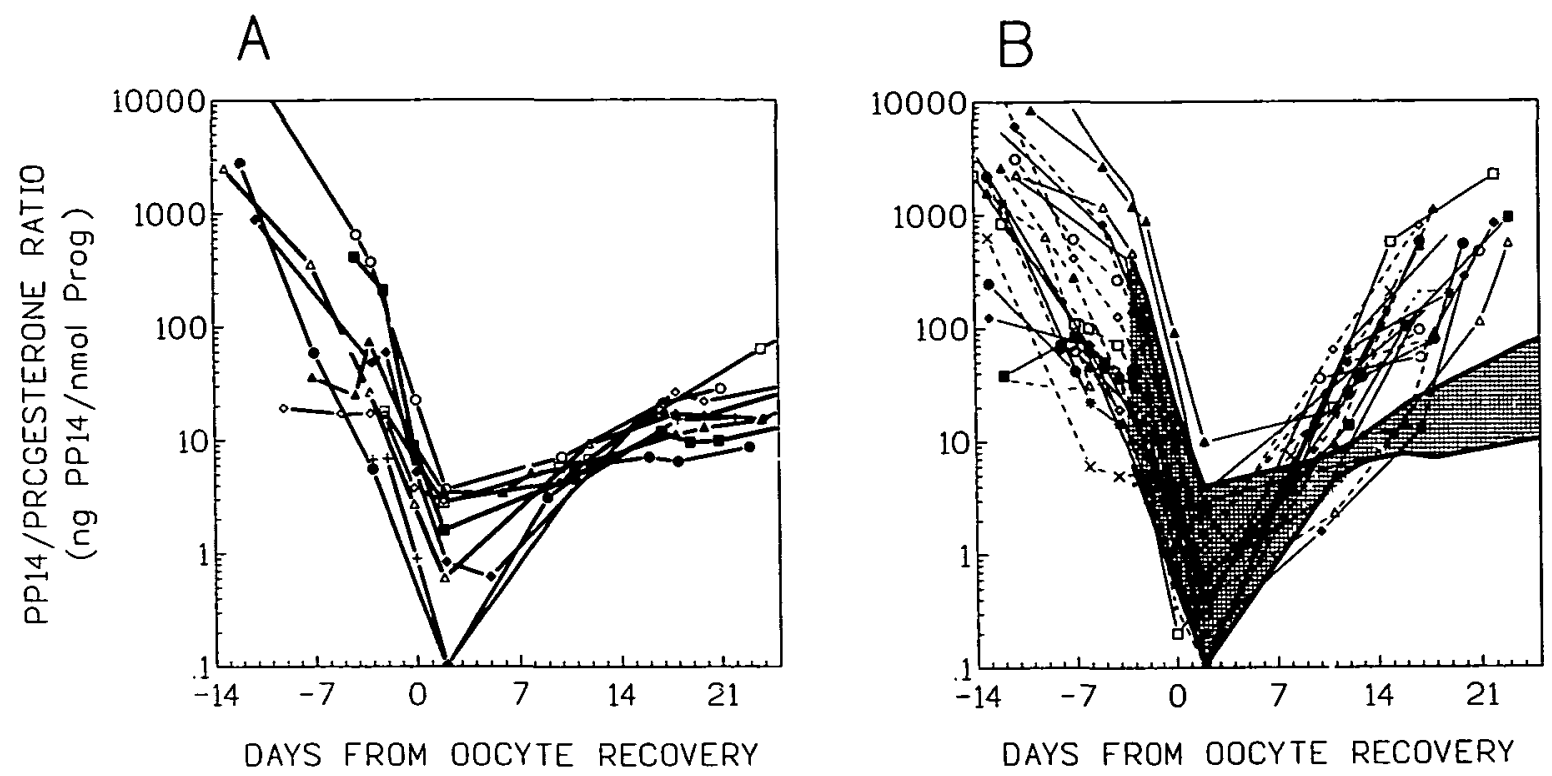

Figure 5. Individual semi-log patterns of the placental protein 14 (PP14) to progesterone ratio in the clinical pregnancy group (A) and in transfer cycles without ongoing pregnancy (B) in both implantation failure (dashed lines) and 'interaction' (solid lines) cycles. The patterns for the pregnancy group after the day of oocyte retrieval -3 are superimposed on $\mathbf{B}$ as a hatched area. The various symbols indicate the individual cycles.

Table I. Median concentrations of serum placental protein 14 (PP14) and progesterone at three different times on and after embryo transfer: comparison between ongoing pregnancy and non-pregnancy cycles

\begin{tabular}{|c|c|c|c|c|c|c|}
\hline \multirow{2}{*}{$\begin{array}{l}\text { Day of cycle relative to day } \\
\text { of oocyte retrieval }\end{array}$} & \multicolumn{3}{|c|}{ Pregnancy } & \multicolumn{3}{|c|}{ No pregnancy } \\
\hline & $n$ & PP14 (ng/ml) & Progesterone (nM) & $n$ & PPl4 (ng/ml) & Progesterone (nM) \\
\hline+2 & 9 & 0.31 & 229 & 24 & $<0.05$ & 159 \\
\hline$+10 / 12$ & 8 & 5.32 & 864 & 19 & 4.20 & 219 \\
\hline$+17 / 21$ & 9 & 17.8 & 1085 & 24 & 40.5 & 8.6 \\
\hline
\end{tabular}

potentially cross-reacting protein is excessively elevated, which cannnot be excluded in pathological situations. We assume that we have measured 'true' $S P_{1}$, but cannot explain its presence in some cycles of our population. Current investigation in our laboratory suggests that some patients are more likely than others to produce abnormal $\mathrm{SP}_{1}$ patterns. Low but significantly positive serum $\mathrm{SP}_{1}$ concentrations at any moment before the day of oocyte retrieval +10 would therefore potentially identify a patient subpopulation with modified biochemical embryo-maternal interaction behaviour and with reduced chances of achieving a pregnancy. The same patientto-patient variation was observed in this study for PAPP-A. Like $\mathrm{SP}_{1}, \mathrm{HCG}$ immunoactivity might also be produced at abnormal cycle times but no measurements were done because of the presence of high (on oocyte retrieval day) or moderate (after embryo transfer) concentrations of exogenous hormone.

The results obtained for these analyses indicate that a certain defined 'ideal' hormonal pattern might have to be followed or at least approximated. $\mathrm{SP}_{1}$ (and maybe PP14) should be as low as possible by the day of oocyte retrieval. Progesterone should not rise too early, an observation made earlier (Fanchin et al., 1993), but a high serum concentration is of course required subsequently which is again reflected in the lower PP14/progesterone ratio in the clinical pregnancies. PP14 must respond to progesterone stimulation but it is important that this response be controlled and not too fast, i.e. the endometrium must not advance faster than the embryo and be out of synchrony. A high progesterone reading (without PPl4 determination) can be as good a pregnancy predictor as the $\mathrm{PP}$ 14/progesterone ratio (progesterone contributes to the ratio to a larger extent than does PP14), but we think that the additional information on the dynamic relationship of the two markers and on the synchrony of the tissues involved is valuable for further investigations. The end-points might have to be refined; in three non-pregnant women, progesterone was still high on the day of oocyte retrieval $+16 / 17$ which made the PP14/progesterone ratio indistinguishable from the pregnancy group (envelope in Figure 5B) at that stage.

No biochemical pregnancies corresponding to the definition of one $\mathrm{HCG}$ reading $>1000 \mathrm{mIU} / \mathrm{ml}$ were observed in our study group, but this could be because we made early diagnostic measurements (HCG, $\mathrm{SP}_{1}$, day of oocyte retrieval+17). However, the boundary between such a biochemical pregnancy and some of our IC cycles is not a sharp one and the three mentioned cycles may fall in this 'grey zone'. The importance of embryo-endometrial synchrony also explains the positive relationship between transferred blastomere numbers and pregnancy rates (Huisman et al., 1994). 
It has been observed, in frozen embryo transfer (Silverberg et al., 1994) as well as in ovum donation (Righini et al., 1994) cycles, that early increases in progesterone did not have the above-mentioned deleterious effect on pregnancy rates encountered in autologous ovarian stimulation. This also points to a possible controlling factor operating between progesterone (i.e. the ovary which is less active in ovum recipients and frozen embryo transfer patients) and PP14 and/or other hormones affecting endometrial differentiation and embryo implantation. Thus it is not the (early) progesterone itself which is responsible for lower pregnancy rates, but both high early progesterone and low pregnancy rates are the consequences of another unknown event. PP14 reflects a more complicated network of interactions than just endometrial output; however, there is no indication as to what role the ectopically produced PP14 might play in the peri-implantation period. Other factors with endocrine, and probably also paracrine, acting mechanisms are involved and further studies, including in-vitro experiments with endometrial explants and embryo conditioned media will be required. At this stage, we suggest that the establishment of a cycle pattern with absent or very low pre-embryo transfer concentrations of PP14 and $\mathrm{SP}_{1}$, and a post-embryo transfer increase in the PP14 to progesterone ratio not exceeding 0.13 log [PP14 (ng)/progesterone (nmol)]/day could be the target to reach (see Figure 5). Further investigations with a large number of cycles are still required, but we conclude that the parameters investigated here will be useful for the diagnostic assessment, particularly in patients with recurrent IVF failure.

\section{Acknowledgements}

We thank $\mathrm{Mr}$ P.Glanzmann for skilful technical assistance, $\mathrm{Mr}$ A.Zakher for valuable help in the development of the ELISA for PP14, and Ms U.Huber for the running of steroid hormone and SP, immunoassays. The monoclonal antibody against PP14 was kindly supplied by Prof. M.Seppala, Helsinki, Finland.

\section{References}

Bell, S.C. and Drife, J.O. (1986a) Secretory proteins of the human endometrium and decidua during menstrual cycle and pregnancy: characterisation of pregnancy-associated endometrial $\alpha_{1}$ - and $\alpha_{2}$-globulins $\left(\alpha_{1}\right.$ - and $\alpha_{2}$-PEG) In Hau, J. (ed.), Pregnancy Proteins in Animals. Walter de Gruyter, Berlin, pp. 143-164.

Bell, S.C., Patel, S.R., Kirwan, P.H. and Drife, J.O. (1986b) Protein synthesis and secretion by the human endometrium during the menstrual cycle and the effect of progesterone in vitro. J. Reprod. Fertil., 77, 221-231.

Bersinger, N.A. (1985) Periovulatory secretion of immunoactive pregnancyspecific $\beta 1$-glycoprotein $\left(\mathrm{SP}_{1}\right)$ in humans: comparison with 'normal' $\mathrm{SP}_{1}$. Ann. Inst. Pasteur/Immunol., 136D, 37-45.

Bersinger, N.A., Zakher, A., Huber, U., Pescia, G. and Schneider, H. (1995a) A sensitive enzyme immunoassay for pregnancy-associated plasma protein A (PAPP-A): a possible first trimester method of screening for Down syndrome and other trisomies. Arch. Gynecol. Obstet., 256, 185-192.

Bersinger, N.A., Brandenberger, A.W., Zakher, A., Dreher, E., Altermatt, H.J. and Birkhauser, M.H. (1995b) Production of endometrial placental protein 14 (PP14) and prolactin by cultured endometrial explants after collagenase and freeze/thaw treatment, and in response to progesterone. Early Preg. Biol. Med., 1, 134-140.

Bischof, P., Haenggeli, L., Sizonenko, M.T., Hermann, W.L. and Sizonenko, P.C. (1981) A radioimmunoassay for the measurement of pregnancyassociated plasma protein A (PAPP-A) in humans. Biol. Reprod., 24, 1076-1081.

Chard, T. and Grudzinskas, J.G. (1985) Placental and pregnancy-associated proteins. In Bischof, P. and Klopper, A. (eds), Proteins of the Placenta. Karger, Basel, pp. 102-113.

Fanchin, R., De Ziegler, D., Taieb, J., Hazout, A. and Frydman, R. (1993) Premature elevation of plasma progesterone alters pregnancy rates of in vitro fertilisation and embryo transfer. Fertil. Steril., 59, 1090-1094.

Grenner, G. (1978) Enzymimmunoassay zur Bestimmung des schwangerschafts-spezifischen $\beta 1$-Glycoproteins. Fresenius $Z$. Anal. Chem., 290, 99.

Huisman, G.J., Leerentveld, R.A., Verhoeff, A. and Zeilmaker, G.H. (1994) IVF results following transfer after 5 days of embryo culture. Hum. Reprod. 9 (Suppl. 4), 33.

Johnson, M.R., Brooks, A., Norman-Taylor, J.Q., Grudzinskas, J.G., Wren, M.E., Murugni, P., Chard, T. and Abdalla, H. (1993) Serum placental protein 14 concentrations in the first trimester of ovum donation pregnancies. Hum. Reprod., 8, 485-487.

Klopper, A., Ahmed, A.G., Bersinger, N.A. and Urbaniak, S. (1985) Placental proteins in male serum. Gynecol. Obstet. Invest., 20, 138-140.

Klopper, A., Ahmed, A.G., Bersinger, N.A., and MacGregor, E. (1986) Placental proteins in seminal fluid. J.' Obstet. Gynaecol., 6, 290-293.

Maguiness, S.D., Shrimanker, K., Djahanbakhch, O., Deeks, J.J., Teisner, B. and Grudzinskas, J.G. (1993) In-vitro synthesis of total protein and placental protein 14 by the Fallopian tube mucosa: variation in relation to anatomical site, the ovarian cycle and the menopause. Hum. Reprod., 8, 678-683.

Righıni, C., Fanchin, R., Olivennes, F., Taieb, J., Leturkornish, H., De Ziegler, D. and Frydman, R. (1994) Premature elevation in plasma progesterone does not affect embryo quality in IVF. Hum. Reprod., 9 (Suppl. 4), 14.

Riitinen, L. (1992) Serous ovarian cyst fluids contain high levels of endometrial placental protein 14. Tumor Biol., 13, 175-179.

Riitinen, L., Narvanen, O., Virtanen, I. and Seppala, M. (1991) Monoclonal antibodies against endometrial protein PPI4 and their use for purification and radioimmunoassay of PPI4. J. Immunol. Meth., 136, 85-90.

Schindler, A.M., Bordington, P. and Bischof, P. (1984) Immunohistochemical localisation of pregnancy-associated plasma protein A (PAPP-A) in decidua and trophoblast. Comparison with HCG and fibrin. Placenta, 5, 227-236.

Seppala, M., Alfthan, H., Vartıainen, E. and Stenman, U.H. (1987) The postmenopausal uterus: the effect of hormone replacement therapy on serum levels of secretory endometrial protein PPI4/ $\beta$ 1-lactoglobulin homologue. Hum. Reprod., 2, 741-743.

Silverberg, K.M., Martin, M., Olive, D.L., Burns, W.N. and Schenken, R.S (1994) Elevated serum progesterone levels on the day of human chorionic gonadotrophin administration in in vitro fertilisation cycles do not adversely affect embryo quality. Fertil. Steril., 61, 508-513.

Received on August 3/, 1994; accepted on May 23, 1995 